A REVOLUTION OF THE SPIRIT 
The revolution of the spirit is a comet flying toward us from beyond the limits of reality.

ANDREI BELY

"Revolution and Culture" 


\title{
A REVOLUTION OF THE SPIRIT
}

Crisis of Value in Russia, $1890-1924$

\author{
Edited by \\ Bernice Glatzer Rosenthal \& \\ MaRTHA BOHACHEVSKY-CHOMIAK \\ Translated by \\ MaRIAN SCHWARTZ
}

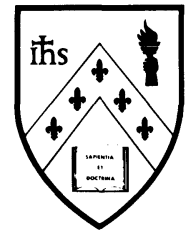

Fordham University Press

New York

1990 
Copyright (C) 1990 by Fordham UnIVERSITY All rights reserved.

LC 90-81779

ISBN $0-8232-1285-8$ (clothbound)

ISBN 0-8232-1286-6 (paperback)

First edition 1982 by Oriental Research Partners

Second edition 1990 by Fordham University Press

$\begin{array}{llllllllll}1 & 3 & 5 & 7 & 9 & 10 & 8 & 6 & 4 & 2\end{array}$

Printed in the United States of America 